\title{
Simulated-firm-based Business Correspondence Teaching
}

\author{
Yan Xiao \\ Shandong Women's University, Jinan, Shandong, China
}

\begin{abstract}
In recent years, simulated firm, increasingly accepted and recommended by educational practioners at home and abroad, has offered a new mode for improving teaching effect. With the aim of teaching business correspondence in a more effective way and creating more chances for majors of economy and trade to do business practice, this paper discusses the feasibility of introducing simulated firm to business correspondence teaching and puts forward a detailed operating pattern which offers a new business correspondence teaching method.
\end{abstract}

KEYWORD: Simulated firm; Teaching method; Business correspondence teaching; Vocational situation

Business correspondence, as a core course of compulsory curriculum for majors of economy and trade, aims at enabling students to write business letters which adhere to international norms and improving their ability of using English in a proper way in foreign trade activities, thus playing a supporting role in training business professionals. With great practicalness and applicability, this course is closely relevant to certain occupational posts, and it involves not only sheer business letter writing, but also the whole import and export business in which English serves as a language carrier. Some procedures involved in foreign trade practices, such as establishing business relationship, trade negotiation, contract fulfillment and settlement of remaining matters after fulfillment, can show importers' and exporters' commercial purposes and trade strategies, and therefore the written language in business correspondence embodies the profit games and interpersonal relationship between two sides of foreign trade (Li Keli, 2007). With the aim of teaching business correspondence in a more effective way and creating more chances for majors of economy and trade to do business practice, this paper discusses the feasibility of introducing simulated firm to business correspondence teaching and puts forward a detailed operating pattern which offers a new business correspondence teaching method.

Simulated-firm-based (SFB) teaching method features a teaching process driven by the whole business procedures of foreign trade which runs through the teaching process like a thread and is divided into different tasks for students. So this method breaks through the traditional course framework based on individual knowledge points, and builds up an occupational-situation-led and taskdriven framework. Meanwhile, acquisition of language skills like the styles, expression and tactics of business correspondence writing is supporting and integrated in each task in the whole teaching process. Simulated firm, as a supplement and even replacement of real business practice, can effectively address the issue of disconnection between business professionals training and corporate needs, thus having become an important teaching mode in higher education.

\section{THE ESSENCE AND THEORETICAL GROUND OF SFB TEACHING}

\subsection{Simulated Firm and SFB Teaching}

Simulated firm, initiated in Germany in 1950s', refers to organized simulated business practices in which an emulated business management platform or setting is built so that students can experience major business operations of a company by learning about the relations among different parts of business without taking any financial risks. The products and services offered by a simulated firm in business operations are not real, but the way it runs, commercial paper, account books, cost and profit calculation are all designed and conducted in the same way as real business does. Students, as the stuff in the simulated company, can act as different 
parts of real business world such as manufacturer, distributor, importer, exporter, raw material supplier and so on, and can also imitate the business relations between the simulated company and customs, industrial and commercial administrative departments, tax authority, logistics and banks respectively. According to positioning of different virtual products and services, students can experience such simulated business activities including trade, marketing, finance, banking, shipment, tariff, insurance and customs.

The core of the SFB teaching method is replacing the traditional teaching mode with a simulated company. By focusing on a single systematic occupational situation, this method can offer students an opportunity to experience the operations of a company which runs in accordance with accepted international business practice and framework and to imitate manufacturing and marketing activities; learning knowledge and skills while doing simulated business, students are actually involved in an inductive learning pattern. With the help of a simulated firm, this teaching method attempts to overcome the problem of disconnection between education and social economy since by creating visualized and vivid environment, what it presents to students is not some empty description of a certain procedure or matter but a certain task, plan or an action that students have to take with some concrete resources at hand. By putting emphasis on action and process, SFB teaching mode offers students potential to overcome the learning difficulties caused by the traditional teaching pattern featuring knowledge delivered by statements and classification (Zheng Jianping, Gerhard Gerdsmeier, 2011).

\subsection{Theoretical Ground for SFB Teaching}

Handlungsorientierung, also named action-oriented teaching theory in English-speaking countries, offers theoretical basis for SFB teaching, and the idea of establishing simulated firm is a successful exploration of action-oriented teaching theory in educational practices. Action-oriented teaching theory has become the mainstream guidance in German vocational education since it was put forward in the late1980s, and has increasingly been accepted and recommended by educational practioners worldwide for it offers a new mode for improving teaching effect. It is accepted in German vocational education that SFB teaching method fits into action-oriented learning theory and constructivism learning theory, and the two theories are the same in essence, though constructivism learning theory was formed and developed on the basis of action-oriented learning theory(Cheng Yongfang, Yan Mingzhong, 2007).

The fundamental of action-oriented teaching is that teaching activities in vocational education are designed, implemented and assessed in accordance with actions required to complete a certain occupational activity, external environment as well as teacher's inner adjustment mechanism. Cultivation of key competencies and occupational abilities are the central idea behind action orientation which proposes that organization of teaching activities should be guided by the needed actions determined by teacher and students so that students can achieve the consistency of mental and manual labor with active and comprehensive learning (Meyer, 1989). With this approach, students are organized purposefully and systematically to participate in the design, implementation, inspection and assessment of occupational practices in a simulated or real professional setting; by discovering, discussing and solving problems in occupational activities, learners can experience and reflect on their learning actions, which can enable learners to convert declarative knowledge into procedural knowledge and ultimately to acquire the knowledge and competencies required to complete relevant occupational practices (Han Maoyuan, 2011).

In teaching, action orientation means that teaching should be oriented by occupational practices; essentially, a kind of simulated setting for social interaction between teacher and students is created, thus generating a hypothesis of behavioral theory. The establishment of simulated company is based on a certain business setting where students take practices as the starting point, scene and objective of learning; by participating in the whole process of deciding tasks, making plans, implementing plans in operation and evaluating works, learners are able to link the current state of ability to act to the state of target ability.

Through repeated drills in SFB teaching, students are expected to develop natural behavioral pattern, intellectual activities and occupational practices that conform to the requirements of real economic activities, and this is to say development should be gained in terms of professional ability, methodology, social ability and individuality (Cui Hongshan, 1999). Therefore, SFB teaching method is a practical exploration into action-oriented educational ideology, embodying the typical characteristics of action-oriented teaching theory.

\subsection{Training Tasks in SFB Teaching}

Based on different phases of business operations, the training tasks in SFB teaching can be roughly 
classified into three types. The first type is the tasks of marketing and designing in the early stage of simulated business, mainly including designing marketing promotion strategies and working out marketing plans, helping students to get acquainted with the early jobs in business operation and to design the strategies for marketing and publicizing their products. Secondly, students can be trained to conduct trade business while the simulated company is running so as to gain a clear insight into the organizational structure, the process of business operation and the rules for running business and enterprise, and to understand how to make and implement decisions for production and management. Thirdly, corporate management training, the training at advanced level, can be offered to students; with the support of simulation software, students are trained in terms of sales planning, cost solution and marketing strategies, specifically marketing purchasing, inventory, manufacturing, $\mathrm{R} \& \mathrm{D}$, human resources management and so on, all of which can offer students an opportunity to experience the real corporate management. However, in business correspondence teaching, the relevant participants involve supplier, manufacturer, agent, purchaser, logistic provider, insurer, bank, and most importantly importer and exporter, and language and letters are carriers in the practices of each procedure of the whole foreign trade operation .

\section{ADVANTAGES OF SFB TEACHING}

\subsection{Close Relevance between Knowledge and Situation}

While conducting a job required for a certain position in a simulated business setting, students are able to get to know the operational mode in a professional job and the relevant action procedures by imitating communication with the insiders and outsiders of the simulated firm and by product and service simulation. Job script makes simulated settings involved in learning tasks so that students manage to activate their inner schematic representation and the corresponding task situation while using knowledge, and in this way the knowledge students have learned can be made more closely related to occupational situations by simulated firm.

\subsection{Easy Conversion from Knowledge to Action}

Through building occupational situations, simulated firm has created the possibility for action, to some extent reproducing the acquisition process. Students are able to get access to knowledge organized in an occupational script. Though students' notion for action can be developed through case method, problem-based teaching, task-based teaching, SFB teaching boasts the special efficacy of teaching thanks to the knowledge based on scripts. SFB teaching, compared with other teaching method, makes it easier to convert knowledge to action minutely and systematically, which is the pronounced edge of this teaching method.

\section{FUNCTION OF SFB TEACHING}

\subsection{Shortening Employment Adaptation Period}

In SFB teaching, teacher selects certain situations as carriers according to different job requirements, and creates specific tasks as teaching content that is organized and practiced in highly simulated business settings. Effective practice of real cases and training of occupational competencies enable students, at the same time as they acquire knowledge and skills, to unconsciously build up certain occupational abilities adequate enough to qualify job requirements so as to shorten employment adaptation period.

\subsection{Making up for Inadequate Practical Teaching Conditions}

Simulated firm creates a highly simulated and multidimensional professional training system in which training tasks cover each procedure of corporate operation so that students can master relevant knowledge in a systematic way. Besides, since all the occupational training can be conducted in classroom, the expense on practical teaching can be cut down; a large amount of fund has to be spent on students' practice in enterprise otherwise. In addition, for some reasons, only a small number of enterprises accept interns, and internship period is relatively long, so internship program is not practical enough. Nevertheless, SFB teaching, with intensive training, can allow students to complete the whole business procedures in a shorter period of time, thus making up for the defects of long internship period and insufficient venues for practice.

\subsection{Strengthening Students' Teamwork}

SFB teaching takes different forms: independent task by self-control, making plans collectively but finishing work independently and in particular, group work. Students' differences and strength determine job distribution, stimulating students' initiative and assuring the consistency of students' interests and positions. Panel discussion, seminar, debate, report and project are conducted within a group for training, and each of these activities would 
be selected for different procedures in business operation, thereby strengthening students' communicative ability and teamwork.

\section{APPLICATION OF SFB TEACHING IN BUSINESS CORRESPONDENCE CLASS}

Business correspondence can not be taught only by refining typical sentence patterns and analyzing model essays, because application-oriented professionals cannot be cultivated without referring to foreign trade practices. The problem of the current business correspondence teaching is that emphasis is usually put only on language, especially the genre features and expressing skills of English. Quite well as students can master the genre features and writing skills of correspondence, they always view foreign trade business involved in letters as "outsiders" due to the disconnection between teaching tasks and students' actual interests, thus failing to realize the relationship among the objectives, strategies and skills of mastering communicative competency and trade practices ( $\mathrm{Li}$ Keli, 2007). Under this circumstance, it is easier for students to have a holistic view of business correspondence that facilitate foreign trade proceeding, if SFB teaching, case study and group work are integrated into business correspondence class. Taking into account such factors as class hours and student quality, this paper proposes three-phase application of SFB teaching to business correspondence class: preparation, utilization and evaluation.

\subsection{Preparatory Phrase}

\subsubsection{Making A plan for Implementation}

A strict logic for working is needed to support SFB mode in business correspondence teaching. Therefore, in order to make sure the course proceeds from phase to phase, the teacher has to conform to the rules that foreign trade procedures go from the simplest to more complex and all procedures are connected, while formulating curriculum standards, designing teaching activities, working out overall planning for SFB teaching and detailed operating plan, and preparing teaching documents like occupational-situation-based task cards, evaluating rules, and rules for labor division.

\subsubsection{Explaining/Encouraging}

Before the class, the teacher should introduce to students the concrete implementation plan of the simulated company, teaching steps, teaching method so as to make sure students are cleart about what to do and how to do in and after class, and their learning objectives and tasks. Meanwhile, simulated firm may be a foreign concept for students and may make their learning tasks more complex, so the teacher must boost students' confidence of integrating this teaching mode in their learning, and raise requirements for this course, which can facilitate the following training programs of the simulated company.

\subsubsection{Making A Survey/Grouping}

After explaining this teaching mode to students, the teacher can ask students a few specific questions through interview or questionnaire, trying to learn about the real situation of students' academic performance and their strength, based on which simulated companies will be set up and students will be assigned to different positions. What should be noted is that the levels of students of different companies should be as close as possible. And then, all these companies need to decide their business scope, design company information including corporate profile, logo, corporate culture, and detailed office address and mailbox, and work out the corporate structure and job responsibilities. Additionally, members of each group are supposed to split up work and cooperate with each other to work out product catalog, product description, packing specifications, prices, all of which are the basis for the later correspondence writing. There are two approaches for each simulated company to look for their trade partner: first, the teacher can appoint the importer and exporter by matching two groups' information; second, students can seek a trade partner on their own according to their products and services.

\subsection{Utilization}

In class, based on a specific occupational situation, the teacher designs teaching activities, determines occupational roles and business procedures, and then creates detailed tasks. The teacher can deliver the teaching content by playing a part of the simulated company, and then demonstrates, evaluates, reflects on the teaching achievements; a complete teaching design can be formed accordingly.

\subsubsection{Pre-class Preparation}

According to the objectives and progress of this course, the teacher needs to carefully design the teaching process including teaching content, division of labor, demonstration, evaluation, the approaches and the time limits for finishing tasks; the documents need to be prepared include list of role assignment information, companies' products, occupational situation, detailed tasks, technical and 
linguistic knowledge related to the situation, sample letters, and forms for process evaluation.

\subsubsection{Discussion for Lead-in}

In this part the teacher introduces an occupational situation to students, guiding students to be involved in it, while the main tasks for students for the time being are to get information, have a detailed understanding of specific tasks and requirements, and be clear about the occupational role they will play. At the same time, the teacher needs to raise the questions which will be discussed later in the occupational situation, and tell students the relevant business and linguistic knowledge. Through brainstorming, students express their opinions and make a good preparation for the implementation of tasks.

\subsubsection{Implementation of Tasks}

SFB teaching takes a student-centered approach to carry out teaching activities. In the phase of implementation, students make plans, split up work, and make decisions and carry out tasks from the angle of a stuff member of a simulated company. Students have become knowledge constructors and the principal part of the job, rather than listeners and observers alone. In contrast, the teacher is no longer the leading role in class, but a class coordinator, playing an assistant role of counselor. Therefore, before the tasks implemented, the teacher should pay special attention to collecting, organizing and summarizing the knowledge relevant to foreign trade in case that students are in need of explanation and guidance when then run into problems. Besides, the teacher needs to supervise the task implementation to make sure the activities go on as anticipated, and offer guidance and raise questions where necessary so as to inspire students' meaning construction and innovation.

\subsubsection{Demonstration of Accomplishment}

Demonstration of students' accomplishments can take various forms: classroom presentation, seminars between companies, and presentation through PPT or files. In this step, competency can result from internalization of knowledge.

\subsubsection{Classroom Comments}

It is in the phase of summary making that students present, reflect on and evaluate their achievements in the project activity. At the end of the class, a summary should be made for students' performance in training, and the leader of each simulated company can be responsible for summarizing, analyzing problems and evaluating their achievements inside their groups. This step is helpful for the teacher to learn about students' problems, puzzlements as well as lessons and experience they have learned. At last, the teacher collects all the information above and makes comments, through which the teacher answers the common problems students have run into, shares experiences, and demonstrates the sample letters to make students rethink their performance. Through such simulated operations, students experience a process of cognition and practice that goes from partial to holistic, from superficial to substantial, from abstract to concrete and from perceptual to rational, thus being able to better consolidate relevant knowledge.

\subsection{Overall Evaluation}

The evaluation mechanism of SFB teaching mode can make full use of the control function of teaching objectives and constantly correct the deviation in teaching activities, making all teaching activities serve the realization of teaching objectives. This evaluation mechanism should be of multiplicity. In terms of evaluating approach, more emphasis should be placed on the evaluation of simulated process of practices which run through the whole course design, instead of on the language skills such as format of writing, expression, writing style and skills; in other words, students' ability of integrating knowledge into practice should be assessed. Action ability which synthesizes professional competency and social ability should be taken as the criterion to judge whether students are qualified for employment requirement. Moreover, evaluation should not be given by the teacher alone; additionally, selfevaluation and evaluation for others should be made by students themselves. In this evaluating mechanism, in order to supervise and control the whole teaching process, evaluation for a student from three sides of teacher, the student himself and other students should cover each layer of course objectives and target each teaching task; evaluation objects should include professional skills, communicative competency, coordinating and organizing ability and problem-solving ability. In this phase, an overall review and evaluation of the utilization of SFB teaching method should be made based on students' feedback, providing reference for teaching in future.

\section{CONCLUSION}

In conclusion, SFB teaching asks students to finish learning tasks through the means of simulated firm. Catalyzing students' meaningful language use and 
creating the supporting environment for language acquisition and internalization, SFB is an effective practical teaching pattern and can enormously promote business correspondence teaching. However, simulated firm, after all, represents a virtual and simplified labor world and bear educational and teaching objectives, thus fundamentally different from the real labor world in terms of target, situation and knowledge type (Zheng Jianping, 2011). Given this, teachers should attach more importance to the design and processing of the learning situation, trying to make it as close as possible to the real world, and should try out various learning tasks and design classroom activity from diverse perspectives; and in this way, adequate support can be offered without damaging students' initiative and openness, allowing students to learn professional skills in a natural process of voluntary output.

\section{REFERENCES}

[1] Chen Yongfang \& Yan Mingzhong.2007.Research on Professional Teaching Theory of German Vocational. Chinese Vocational and Technical Education (8): 54.

[2] Cui Hongshan.1999. "Simulated Frim" and Actionoriented Teaching. Chinese Vocational and Technical Education (5):51-52.

[3] Han Maoyuan. 2011. Theoretical and Practical Interpretation of Action-oriented Teaching. Heilongjiang Researches on Higher Education (6):146-148.

[4] Li Yuchun \& Shi Liyuan \& Ni Chunli. 2006. Simulated Firm: An Effective Practical Teaching Method for Higher Vocational Education. Chinese Vocational and Technical Education (6):42-44.

[5] Li Keli.2007.Communicative Teaching Method and Business Writing Teaching. Hunan Agricultural Machinery (6):70.

[6] Zheng Jianping \& Gerhard Gerdsmeier.2011.Analysis on the Typical Problems Existed in the Teaching of Practice Firm of Vocational Schools. Vocational and Technical Education (1):19-23. 